\title{
Hybrid Electro Vehicle
}

\author{
P. Vidhyalakshmi, S. Vijayadharan, C. Shanmathi, V. Raahul, R. Logesh
}

\begin{abstract}
Now-a-days, the environmental impact of automobiles is increasingly becoming one of the most important social issues. Major environmental impact is smog producing gases [2]. These gases emitted from the vehicles may pollute the air, water, soil and it results in acid rain, global warming, nausea and also leads to death. To meet current and future regulations with less emission of gases, alternative technologies like Hybrid Electric Vehicle (HEV) is being developed. A $H E V$ is a type of hybrid vehicle that combines a conventional Internal Combustion Engine (ICE) system with an electric propulsion system. These hybrid vehicles reduce the discharge of pollutants from the vehicles powered by fossil fuel. These vehicles are propelled by electric motors which is powered by the energy stored in the batteries [5]. The battery charges when the vehicle is in running condition. HEVs are fuel efficient and is good to the environment. It produces twice as many miles per gallon. The presence of this method is intended to achieve either better fuel economy than a conventional vehicle.

Keywords: ICE, Fossil Fuel, Hybrid Vehicle, Automobiles, Battery and Fuel Efficient.
\end{abstract}

\section{INTRODUCTION}

HEV combines a conventional Internal Combustion Engine (ICE) system with an electric propulsion system. The introduction of this hybrid technology is to develop the pollution free nation. Now a days, battery used in vehicles have limited life time when compare to the battery used in hybrid vehicle. Because when the battery gets drained there is a need for an external charger to charge the battery. But in this method, vehicle runs only with the help of battery [5] and the battery will be charged when the vehicle is running and there is no need for an external charger. The energy stored in battery is used for head lights, meters, indicators etc. The fuel used in the vehicle is only to run the engine. HEV is fuel efficient and reduce the pollution. In recent days, usage of normal conventional vehicle is reducing in foreign countries and they are switching towards hybrid vehicle [7]. In hybrid vehicle, the battery is rechargeable and it has long life span. There is no need of external charger to charge the battery. The battery will be charged only with the help of alternator rpm (revolution per minute). Vehicle requires constant voltage for their movement.

Revised Manuscript Received on June 01, 2020.

*Correspondence Author

P. Vidhyalakshmi, Assistant Professor, Department of Electronics and Instrumentation Engineering, Kongu Engineering College Perundurai, Erode (Tamil Nadu), India.

S. Vijayadharan, Student, Department of Electronics and Instrumentation Engineering, Kongu Engineering College Perundurai, Erode (Tamil Nadu), India.

C. Shanmathi, Student, Department of Electronics and Instrumentation Engineering, Kongu Engineering College Perundurai, Erode (Tamil Nadu), India.

V. Raahul, Student, Department of Electronics and Instrumentation Engineering, Kongu Engineering College Perundurai, Erode (Tamil Nadu), India.

R. Logesh, Student, Department of Electronics and Instrumentation India.

(C) The Authors. Published by Blue Eyes Intelligence Engineering and Sciences Publication (BEIESP). This is an open access article under the CC BY-NC-ND license (http://creativecommons.org/licenses/by-nc-nd/4.0/) Engineering, Kongu Engineering College Perundurai, Erode (Tamil Nadu),

Thus, constant voltage can be acquired with the help of a voltage regulator. These vehicles are environmental friendly, less resale value, financial benefit and less dependency of fossil fuel.

The presence of this hybrid method is intended to achieve either better fuel economy than a conventional vehicle. The main objective of hybrid vehicle is to charge the battery with the help of alternator. Here, the engine will be initiated by using starter. Engine shaft is connected to the alternator shaft. The output from the alternator is given to the battery after rectification and regulatory operation. The energy stored in the battery is given to the control unit and motor for further process.

\section{LITERATURE REVIEW}

Vinay K.M and Isaac Raj [1] have designed a paper on the topic hybrid vehicle. The main idea of their paper is to run the wheels only with the help of motor. The components required are regenerative braking system, hybrid engine, electric motor and battery. The motor will run by using battery. The advantages of this system is increased power and improved fuel economy. But their drawback is that, the battery will not undergo charging while the vehicle is running, it undergoes when the vehicle is in standstill condition. The disadvantage of regenerative braking system is it offers sliding scale of benefits i.e there will be more energy loss when the speed is decreasing.

Omesh Heman Kumar and Manohar [4] have published the paper on the topic named Smart Electric Vehicle (SEV). It provides large potential to save fuel consumption and reduce pollutant emission. An SEV is a vehicle driven by more than one power source. To detect the distance between the vehicle and the obstacles, ultrasonic sensor is fixed on the front side of the car. In this vehicle, $1 \mathrm{KiloWatt}(\mathrm{KW})$ solar panel is used to charge the batteries. The type of the batteries used here is lithium-ion battery 48Volt (V), 60Amp (A). This charging can be done during day time while the vehicle is at rest. Lithium-ion battery requires high maintenance, ageing and high cost. Ultrasonic sensor covers only certain distance upto a maximum of 20 meter and it is very sensitive to temperature.

\section{PROPOSED SYSTEM}

In our project, the above drawbacks have been solved. The energy required for the battery is obtained through alternator. The alternator provides constant

voltage to the battery by rectifying and regulating operation. The battery of this vehicle is rechargeable. This vehicle's dependency of fossil fuel and maintenance is comparatively lesser than the normal vehicle.

\section{Published By:}

Blue Eyes Intelligence Engineering \& Sciences Publication 


\section{Hybrid Electro Vehicle}

These vehicles are propelled by electric motors which is powered by the energy stored in the batteries. HEVs are fuel efficient and is good to the environment. By using these hybrid vehicles, the pollution have been reduced and it leads to the safe and healthy environment.

\section{METHODOLOGY}

When the engine is started, the starter motor turns the crankshaft which in turn gets the pistons moving in the cylinders. This starts the engine cycle. This movement helps in rotating the alternator to produce output current. Vehicle requires only Direct Current (DC) input to move on. But the output from the alternator is Alternating Current (AC). This AC can be converted into DC by using rectifier. The output from the rectifier can be regulated through voltage regulator. The regulated voltage is given to the battery. The battery stores energy and this can be given to the control unit for controlling the head light, horn and also to the motor for movement.

\section{BLOCK DIAGRAM}

\section{THE FIGURE 1 SHOWS THE BLOCK DIAGRAM FOR HEV.}

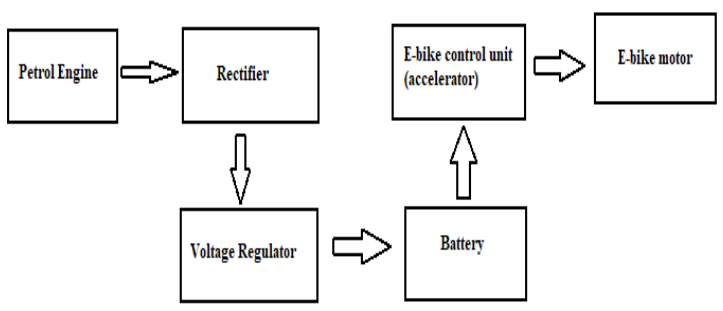

\section{FIG 1 BLOCK DIAGRAM OF HEV}

\section{DESCRIPTION}

The description of the individual blocks are explained below. The engine is started by using a starter. The shaft of the engine is connected to the shaft of the alternator. During ignition when the shaft of the engine rotates the shaft of the alternator also rotates. The alternator revolution may vary with respect to engine shaft. With respect to rotation, an alternator produces an output in the range of $(20-24) \mathrm{V}$ and (3-7)A AC. The AC is converted into DC with the help of rectifier. The output from the rectifier is given to the voltage regulator to regulate the DC output from the rectifier [3]. The regulated $\mathrm{DC}$ voltage from the voltage regulator is given to the $12 \mathrm{~V}, 7 \mathrm{~A}$ battery for charging. Here two $12 \mathrm{~V}$ batteries are connected in series and these batteries are charged by the output from the regulator. These two batteries produces an voltage of $24 \mathrm{~V}$. This constant $24 \mathrm{~V}$ is given to the DC gear motor for further operation. This process continues and the battery undergoes charging when the vehicle is in running condition. The main advantage is that the vehicle run only with the energy stored in the battery. External charger is not required to charge the battery and this charging process is done when the vehicle is in running condition.

\section{HARDWARE REQUIREMENTS}

\section{THE FOLLOWING ARE THE COMPONENTS OF HEV.}

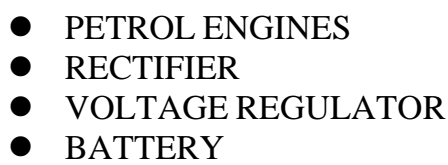

\section{A. Petrol Engines}

ICE is the combustion of fuel with oxygen of the air occurs within the cylinder of the engine. Based on the ICE classification, petrol engine is the best method of fuel supply to the engine cylinder. A petrol engine is an ICE with spark ignition system, designed to run on fuel. ICE is a heat engine where the ignition of a fuel happens with an oxidizer (normally air) in a burning chamber that is an essential piece of the working fluid flow circuit. Two types of stroke take place in an engine. One is upward stroke and other is downward stroke. During upward stroke of piston, the gases are compressed and at the same time fresh air and fuel mixture enters the crank chamber. When the piston moves downwards, the mixture in the crank chamber is compressed and produces an explosive change. Again, when the piston is moving upwards and is compressed to produce an explosive change. Ignition takes place only at the end of the stroke.

\section{B. Rectifier}

A rectifier is an electrical device that converts AC, which periodically reverses direction to, which flows in only one direction. This process is known as rectification, since it straightens the direction of current. The output from the alternator is in the form of AC and it is converted into DC by using rectifier. Output from the alternator may vary with respect to speed. Depending on the type of alternator output current supply and the arrangement of the rectifier circuit, the output voltage from the rectifier may require additional smoothing to produce a uniform steady voltage. They have low power loss because no voltage signal is wasted in the process of rectification.

\section{C.Voltage Regulator}

Voltage regulator regulates the output of the rectifier based on its input to the battery [3].7824 Voltage controller is a kind of independent fixed direct voltage controller coordinated circuit. The IC has a place with $78 x x$ voltage controller family which is usually utilized as the managed force supply in electronic circuits. The 7824 voltage controller IC is convenience and accessible in ease. The last two digits of 7824 demonstrates the yield voltage that is voltage. The 7824 IC have 3 pins, pin 1 is a positive info, pin 3 is a positive yield and pin 2 is negative shared opinion between both contribution just as yield voltage

The 7824 Voltage controllers do work at their ideal ability if the information voltage is in any event 2.5 volt more prominent than the yield voltage and the current is 1 or 1.5 Amperes more. 


\section{D.Battery}

The lead-acid battery is one of type of rechargeable battery. The battery will be charged when the vehicle is in running condition. The battery will be charged when the vehicle is in running condition. The energy stored in the battery is given to the motor, indicator, control unit etc. Scope of one battery is 12V-7A. Two batteries are utilized here. These batteries when connected in series produces a voltage of $24 \mathrm{~V}$. In the completely energized express, the negative plate comprises of lead, and the positive plate lead dioxide. The electrolyte is concentrated sulphuric acid, which stores the vast majority of the concoction vitality. Lead-acid battery contains a blend with differing centralizations of water and corrosive.

\section{E.E-Bike Control Unit}

Control units gets energy only from the battery. It consists of horn, headlight, indicator etc. These units will be in ON condition only when the battery supplies energy. This energy from the battery is obtained through alternator.

\section{F. Bike Motor (Dc Geared Motor)}

A DC engine is a class of revolving electrical machines that changes over direct flow electrical force into mechanical force. Geared motors are a DC Motor with a gearbox fitted to the front of the motor. DC Geared motor are automotive and used for Prototyping applications. DC geared motor of $24 \mathrm{~V}$ is used in this method. There will be a increase in speed, when there is a increase in acceleration. The output from the motor depends upon the acceleration. The supply is given to the motor only with the help of battery. The motor runs only with the energy of battery and not by the fuel.

\section{RESULT AND ANALYSIS}

Parameters of Vehicle Under Various Load And Unload Condition

The load is applied in the form of low, medium and high by controlling throttle. The following tables shows the various parameters of vehicle under various loading condition.

Table 1.1: Parameters of Rectifier Under Load And No Load Condition

\begin{tabular}{|c|c|cc|c|}
\hline $\begin{array}{c}\text { UNDER } \\
\text { LOADAND } \\
\text { NO LOAD }\end{array}$ & BATTERY & $\begin{array}{c}\text { MOTOR } \\
\text { PARAMETERS } \\
\text { VOLT(V) } \\
\text { AMP(A) }\end{array}$ & $\begin{array}{c}\text { POWER } \\
\text { P=V*I }\end{array}$ \\
\hline NO LOAD & ON & 22.1 & 1.99 & 43.9 \\
\hline LOAD & ON & 21.9 & 2.54 & 55.62 \\
\hline LOAD & ON & 21.8 & 2.91 & 63.43 \\
\hline LOAD & ON & 21.2 & 4.66 & 98.79 \\
\hline LOAD & ON & 21.1 & 3.68 & 77.64 \\
\hline LOAD & ON & 21.9 & 3.53 & 76.65 \\
\hline
\end{tabular}

Table 1.2: Parameters of Motor Under Load And No-Load Conditions

\begin{tabular}{|c|c|cc|c|}
\hline $\begin{array}{c}\text { UNDER } \\
\text { LOAD/NOL } \\
\text { OAD }\end{array}$ & $\begin{array}{c}\text { BATTER } \\
\text { Y }\end{array}$ & \multicolumn{2}{|c|}{$\begin{array}{c}\text { RECTIFIER } \\
\text { PARAMETERS } \\
\text { VOLT(V) } \\
\text { AMP(A) }\end{array}$} & $\begin{array}{c}\text { RECTIFIE } \\
\text { R POWER } \\
\text { P=V*I }\end{array}$ \\
\hline $\begin{array}{c}\text { NO } \\
\text { LOAD }\end{array}$ & OFF & 25.5 & 0 & 0 \\
\hline LOAD & ON & 25.5 & 2 & 51 \\
\hline LOAD & ON & 25.5 & 1.5 & 38.25 \\
\hline LOAD & ON & 25.5 & 1 & 25.5 \\
\hline LOAD & ON & 25.5 & 0.5 & 12.75 \\
\hline LOAD & ON & 25.5 & 0 & 0 \\
\hline
\end{tabular}

Table 1.3: Voltage Level of Alternator and Rectifier

\begin{tabular}{|c|c|}
\hline ALTERNATOR(V) & RECTIFIER(V) \\
\hline 16 & 4 \\
\hline 17.4 & 7 \\
\hline 20 & 8.8 \\
\hline 22 & 9.6 \\
\hline 26.4 & 11.2 \\
\hline 34 & 12.1 \\
\hline 36 & 13 \\
\hline
\end{tabular}

Table-1.4: Battery Discharge (No Load Conditions)

\begin{tabular}{|c|c|}
\hline TIME(MIN) & BATTERY(V) \\
\hline 0 & 23.6 \\
\hline 10 & 22.6 \\
\hline 20 & 21.3 \\
\hline 30 & 20.4 \\
\hline 40 & 19.2 \\
\hline 50 & 18.1 \\
\hline 60 & 17.2 \\
\hline 70 & 16.1 \\
\hline
\end{tabular}

Table 1.5: Full Throttle-Charging

\begin{tabular}{|c|c|}
\hline TIME (SEC) & BATTERY(V) \\
\hline 0 & 0 \\
\hline 5 & 5.4 \\
\hline 10 & 10.5 \\
\hline 15 & 15.3 \\
\hline 20 & 20.1 \\
\hline 22 & 22.2 \\
\hline
\end{tabular}




\section{Hybrid Electro Vehicle}

\section{CONCLUSION}

On comparing with normal vehicle, the hybrid vehicle will be more efficient. Because, normal vehicle is fully relying on petrol while hybrid vehicle runs with the help of energy stored in the battery. By this means, distance coverage for the same amount of fuel will be high when comparing with normal vehicle. Also, hybrid vehicle reduces the dependency on fossil fuel. Less dependence on fossil fuel may reduce the pollution released from vehicles and also the harmful effects threatening the atmosphere. It also reduces the greenhouse gases. Hence, hybrid vehicle has more advantages than a normal conventional vehicle and it is the best method to overcome the drawbacks of normal vehicle.

\section{Hardware Setup}

The figure 2 shows the hardware setup of hybrid electro vehicle

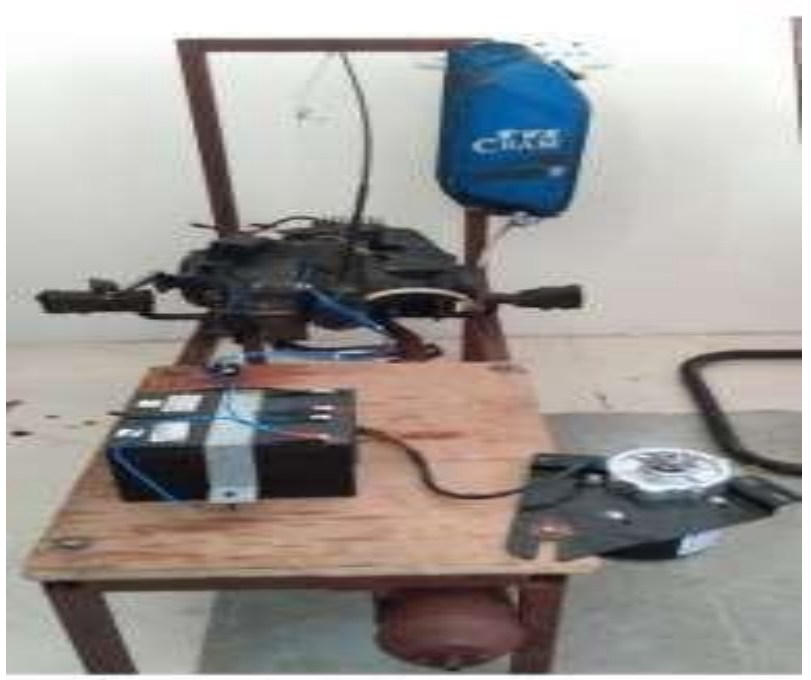

Fig 2 Hardware Setup of HEV

\section{FUTURE SCOPE}

To have a cleaner and greener environment, hybrid vehicles have been introduced. Improved mileage and decreased fuel utilization, is a significant advantage of hybrid vehicles. It results in less emission of harmful gases into the environment and also avoids the release of toxic substance or gases.

\section{REFERENCES}

1. Vinay K.M and Isaac Raj (2017), "Hybrid Vehicle", International journal of engineering trends and technology (IJETT), volume 50, Number 2.

2. Satti Swami Reddy, Kola Siva Tharun, "Eco Friendly Vehicle", International Journal of Engineering Trends and Technology (IJETT), 4(4), April 2013, 957-960.

3. Trajkovic, S., Tunestal, P., and Johansson, B., "Vehicle Driving Cycle Simulation of a Pneumatic Hybrid Bus Based on Experimental Engine Measurements", SAE Technical Paper 2010-01-0825, 2010, doi :10.4271/2010- 01-0825.

4. Omesh Heman Kumar and Manohar (2015), "Smart Electric Vehicle", IOSR Journal of Mechanical and Civil Engineering, Volume 12, PP 11-14.

5. Joeri Van Mierlo (2018), "The World Electric Vehicle Journal", doi:10.3390/9010001.

6. Ryan Sprague (2015), "An Analysis of Current Battery Technology and Electric Vehicles", Journal of Undergraduate Research.

7. K.W.E Cheng, "Recent Development of Electric Vehicles", International Conference on Power Electronics Systems and Applications, Digital Reference: K2109001.

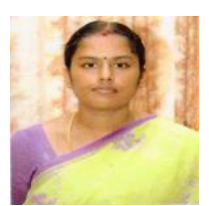

\section{AUTHORS PROFILE}

P. Vidhyalakshmi, Assistant Professor (Sr.G) in the Department of Electronics and Instrumentation Engineering at Kongu Engineering College Perundurai, Erode.

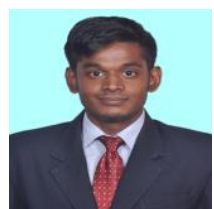

S. Vijayadharan, studying B.E final year in the stream of Electronics and Instrumentation Engineering at Kongu Engineering College, Perundurai, Erode.

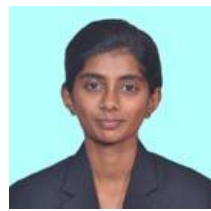

C. Shanmathi, studying B.E final year in the stream of Electronics and Instrumentation Engineering at Kongu Engineering College, Perundurai, Erode.

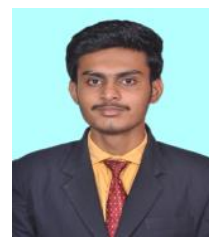

V. Raahul, studying B.E final year in the stream of Electronics and Instrumentation Engineering at Kongu Engineering College, Perundurai, Erode.

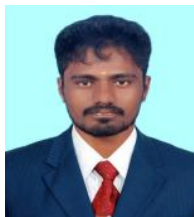

R. Logesh, studying B.E final year in the stream of Electronics and Instrumentation Engineering at Kongu Engineering College, Perundurai, Erode. 